\title{
Pilar Nieto Alderete
}

\author{
João Carlos Pinto Dias ${ }^{1}$ e José Rodrigues Coura ${ }^{2}$
}

Pilar Alderete nasceu no interior do Chaco, região pobre e seca, altamente endêmica para doença de Chagas. Ali haviam trabalhado Freire, Bravermann, Corsi e Salica, colaboradores diretos de Salvador Mazza. Nas redondezas, Romaña vira os primeiros casos agudos com seu notório sinal. Mais recentemente, Yanowsky, Burli, Schmuniz, Gualtieri, Nasir e Storni deixaram importantes trabalhos ${ }^{7}$. Pilar vivera em Villa Angela e Resistencia, visitara J. Castelli por inúmeras vezes, conhecia a fundo as tristezas e belezas do "Impenetrable", região agreste dos Tobas e Matacos. Apreendera, em sua juventude, a postura forte e jamais resignada dos chaquenhos. Embalados pela brisa morna, às vezes atropelada pelo gelado vento do sul, os filhos do Chaco são suaves e aguerridos, são pacientes e têm pressa. São ternos e fortes, também, à moda de seu amado palo santo, um lenho nativo e emblemático que perfuma seu entorno, resiste à seca e acolhe a todos em sua sombra. A par o solo árido e o clima agreste, um dos mais tremendos desafios do Chaco reside na elevada dispersão da vinchuca, o inseto temerário e traiçoeiro transmissor do mal de Chagas. Ranchos muito toscos, dia a dia na sobrevivência, paredes e tetos trincados, pobres gentes insuladas e desprotegidas, eis o cenário habitual da expansão da endemia. Pilar o sentia muito forte, enternecia-se com as crianças barrigudas e os magros cachorros, que apelidava "de mirada triste". Foi à pesquisa e aprendeu a multiplicar em sua volta a herança de cuidado e de luta que portava em sua história de vida. Desenvolveu extraordinária capacidade de trabalho e

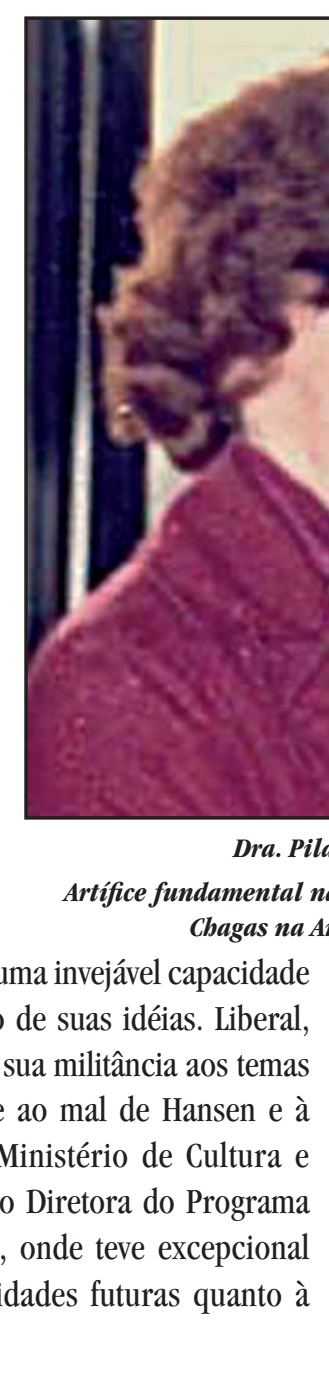

En este momento estamos empeñados no solo en el incremento y en el mayor apoyo a este programa, sino en establecer relaciones con los demás países que desarrollan acciones o programas similares. Entendemos que la coordinación y la concertación de acciones y de proyectos de investigación interpaíses nos llevará a avanzar más en el conocimiento de la endemia, pues el problema de Chagas es americano y lo tenemos que solucionar entre todos ${ }^{1}$.

Pouco a pouco contatou e incorporou em sua lide os principais grupos de investigação sobre doença de Chagas de seu país, entendendo que do âmbito científico sairiam as melhores motivações para uma ação política maior, assim como era preciso tirar os avanços tecnológicos das bancadas e congressos médicos de articular, motivar pessoas em torno de suas idéias. Liberal, amável e grande observadora, dedicou sua militância aos temas prevalentes em seu País, notadamente ao mal de Hansen e à doença de Chagas. Incorporada ao Ministério de Cultura e Educação, foi nomeada em 1978 como Diretora do Programa Nacional de Enfermidades Endêmicas, onde teve excepcional desempenho e prenunciava suas atividades futuras quanto à tripanossomose, já em 1979: foi incorporando ao seu brilho natural uma invejável capacidade para inseri-los, de fato, nas fronteiras de serviço. Assim, Pilar rapidamente estabeleceu suas relações de cooperação e cumplicidade na Argentina e alhures. Envolveu entomologistas, bioquímicos, cardiologistas, hematólogos, pediatras, clínicos, sociólogos, educadores e chefes de programa. Foi aos congressos e serviços sobre doença de Chagas no Brasil, no Chile e no Uruguai, além de palmilhar as Províncias endêmicas de seu País, amealhando amigos e colaboradores. Idealizou paulatinamente um projeto ambicioso de serviço e extensão de conhecimentos na esquizotripanose, que aprovou no Banco Interamericano do Desenvolvimento (BID $)^{13}$. Para tanto, como havia exigência de participação de uma Instituição de Ensino, fez-se professora e pesquisadora da Universidade del Salvador, em Buenos Aires, conveniando-a ao Ministério de Saúde e Ação Social da Argentina, ao início dos anos 1980. 0 Programa de Salud Humana foi montado e sempre dirigido por Pilar. 0 modelo formulou-se na composição de um grupo transdisciplinar de pesquisadores e profissionais dedicados aos temas do vetor e seu controle, dos bancos de sangue, do diagnóstico (sorológico e parasitológico), da clínica e terapêutica de crônicos e agudos, e da educação em saúde, voltados para a doença de Chagas. Seminários regionais, publicações informativas, assessoramento direto aos serviços nacionais e provinciais, emissão de bolsas de

1. Centro de Pesquisas René Rachou e Posto Emmanuel Dias, Fundação Oswaldo Cruz, Belo Horizonte, MG. 2. Instituto Oswaldo Cruz, Fundação Oswaldo Cruz, Rio de Janeiro, RJ. Endereço para correspondência: Prof. João Carlos Pinto Dias. Centro de Pesquisas René Rachou/FIOCRUZ. Av. Augusto de Lima 1715, Barro Preto. 30190-002 Belo Horizonte, MG, Brasil.

E-mail: jcpdias@cpqrr.fiocruz.br 
treinamento e capacitação, tudo foi previsto. Nas províncias e países contemplados, a articulação se fazia obrigatoriamente com os serviços governamentais e as instituições oficiais de ensino e pesquisa, sempre buscando aproveitar a expertise local. Sabiamente, para que não se perdesse a motivação, cada curso deixava implantada uma unidade de diagnóstico (com microscópio de imunofluorescência e reagentes para TIFi e HAI), outra de eletrocardiografia (com aparelho Toshiba ${ }^{\circledR}$ oferecido) e uma terceira de entomologia (com lupa e material de análise sistemática).

Para ter-se uma idéia, participaram efetivamente destas atividades pesquisadores de renome como M. Rosenbaum, $\mathrm{H}$. Lugones, E. Kushnir, J. Yanowsky e P. Chiale (Argentina), R. Salvatella (Uruguai), H. Schenone (Chile) e vários brasileiros como Z. Brener, JR Cançado, A. Prata e JR Coura. Muitos outros ficaram agregados ao Programa e participavam da maioria das atividades, citando-se E. Manzullo, O. Ledesma, G. Martini, F. Peralta, M Rosalén, E. Segura, A. Stoppani, C. Ripoll, H. Sgammini, E. Alvarez, P. Moya, N. Arguello, A. Marteleur, G. Barbieri, J. Molina e JC Pinto Dias, entre tantos mais. Formou-se uma família, que Pilar acolhia e estimulava incansavelmente, a palmilhar toda a área endêmica argentina, entre 1982 e 1989, alternandose com cursos similares no Uruguai, no Chile, na Bolívia, no Brasil, no Paraguai e em Honduras. Imensamente trabalhoso, este Programa absorvia totalmente as energias de Pilar, à época ajudada por sua filha Ethel e por companheiros inseparáveis como Nora, Norma, Leonardo, Cabanilla e Maria Angélica. As atividades foram ininterruptas e o Programa alcançou grande sucesso, sendo aprovado com distinção pelo BID. Formaram-se muitos quadros atuantes nas diversas áreas, estimulou-se a luta anti-vetorial, equiparam-se bancos de sangue, criou-se ampla mentalidade de cuidado para com infectados agudos e crônicos. Dessas atividades e cursos emergiram eficazes lideranças que vieram a capitanear os programas regionais e nacionais de controle da doença na Bolívia, no Uruguai, no Paraguai e na própria Argentina. Indubitavelmente, do exercício deste Programa, Pilar Alderete ajudou a fincar as raízes do que viria a ser, poucos anos depois, a "Iniciativa do Cone Sul" 34 . Além dos cursos e treinamentos, o Programa realizou investigações próprias sobre prevalência da infecção, controle e vigilância de triatomíneos, pedagogia de participação popular, especialmente. Fez também um minucioso levantamento da produção científica da Argentina, estimulando o mesmo para o Uruguai, Bolívia e Costa Rica. De passagem, publicou um livro sobre clínica e terapêutica da tripanossomose, de ampla circulação, e editou após seminários técnico-científicos, um manual de atenção ao infectado e outro de critérios eletrocardiográficos ${ }^{1256}$. Ao final de dez anos de labor intenso, já uma vez renovado, o Programa foi encerrado, com aprovação total do Governo Argentino e do BID, também se recolhendo a este último uma pequena sobra de recursos não gastos.

No trajeto, Pilar fez reviver, em 1984, o Comitê Científico Internacional de Luta Contra a Doença de Chagas, com eminentes representantes em 16 países e participação assessora da OPS e da OMS. Foi sua presidente até 89, tendo Carlos Chagas Filho como presidente de honra. Este Comitê proporcionou enorme e frutífero intercâmbio entre pesquisadores e sanitaristas, em particular estimulando o controle de bancos de sangue, a vigilância entomológica, a colaboração entre países, a produção de bibliografias e a questão laboral/previdenciária do infectado. Terminado o Salud Humana, Pilar deu-lhe sequiência através do Rotary Internacional, mantendo os treinamentos e ampliando as atividades para a América Central e o México. Envolveu-se mais recentemente com a Universidade Católica de Salta, onde se tornou professora de um curso internacional em moléstias tropicais, dirigido pela amiga Amália Segovia. Por opção, foi morar em Santiago del Estero, ao lado de Humberto Lugones e outros queridos amigos, onde até há pouco chefiava o Programa Provincial de Controle da Doença de Chagas e o sistema de atenção primária à saúde. Grande amiga do Brasil, compareceu a inúmeras reuniões e congressos em nosso País, aqui promovendo um memorável seminário de capacitação, deixando um laboratório de imunofluorescência em Uberaba, apoiando as pesquisas de Bambuí e delegando à Fiocruz a continuação do Comitê Científico Internacional. Par e passo, Pilar nunca se descuidou de sua querida família, acompanhando a doença e morte de seu esposo Dr. Alderete e apostando todas as suas fichas no crescimento e sucesso de sua filha Ethel e suas netinhas Pilar e Magdalena.

Neste início de primavera austral, em 2008, Pilar nos deixou, aos 85 anos. Trabalhou até o fim, nunca esmoreceu, nada reclamou. Foi-se dignamente uma grande amiga e companheira. A Argentina e toda a América Latina perderam uma grande guerreira contra as nossas inimigas comuns: as vinchucas e a doença de Chagas. Que Deus reserve para Pilar o melhor lugar no céu. As crianças Latinoamericanas, livres da doença de Chagas, cantarão para ela seu suave canto de amor e de gratidão.

\section{REFERÊNCIAS}

1. Alderete PN. La investigación en la enfermedad de Chagas. In Posse R, Mouzo G, Barrio N (organs.) Enfermedad de Chagas. Buenos Aires, Ministério de Salud de Argentina, p. 37-40, 1981.

2. Dias JCP. Enfermedad de Chagas. Epidemiología, clínica, terapeutica. Buenos Aires, Programa de Salud Humana., 106p., 1984.

3. Dias JCP. Southern Cone Initiative for the domestic populations of Triatoma infestans and the interruption of transfusional Chagas Disease. Historical aspects, present situation and perspectives. Memórias do Instituto Oswaldo Cruz 102 (Suppl. I): 11-18, 2006.

4. Dias JCP, Schofield CJ. The Evolution of Chagas Disease (American Trypanosomiasis) Control after 90 years since Carlos Chagas discovery. Memórias do Instituto Oswaldo Cruz 94 (Suppl. I): 103-122, 1999.

5. Programa de Salud Humana. Normas para la atención médica del infectado chagásico. Buenos Aires. Ministerio de Salud y Acción Social, 17 p., 1983.

6. ProgramadeSalud Humana. Nomeclaturay criterios de diagnostico electrocardiográfico. Buenos Aires. Ministerio de Salud y Acción Social, 28 p., 1985.

7. Segura EL. El Control de la Enfermedad de Chagas en la República Argentina. In Silveira AC (organ.) El control de la enfermedad de Chagas en los Países del Cono Sur de América: historia de una iniciativa internacional, 1991-2001. OPAS, Universidade Federal do Triângulo Mineiro, Uberaba (Brasil), p. 45-108, 2002. 